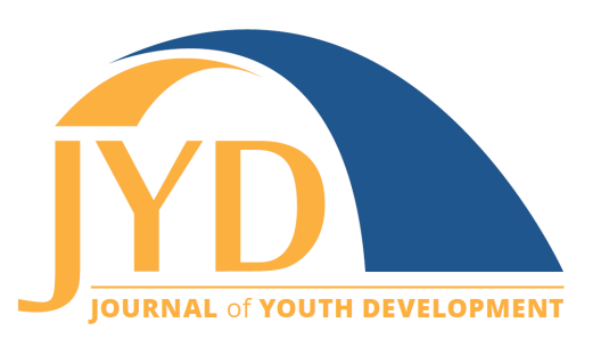

http://jyd.pitt.edu/ | Vol. 16 Issue 2-3 DOI 10.5195/jyd.2021.1032 | ISSN 2325-4017 (online)

\title{
Designing a Character Strengths Development Program for Youth Living in Violent Contexts
}

\author{
Betsabé Vásquez \\ Glasswing International, El Salvador \\ bvasquez@glasswing.org \\ Lelys Dinarte Díaz \\ Development Research Group, The World Bank \\ Idinartediaz@worldbank.org
}

\begin{abstract}
This paper describes the design and piloting of a Character Strengths Development (CSD) curriculum for Glasswing International's after-school program. The CSD curriculum was designed to be implemented in EI Salvador, Honduras, and Guatemala, countries that make up the Central American Northern Triangle (NTCA) and have extremely high rates of violence and criminality. Development of the CSD curriculum included 3 stages: a consultative process with youth, review of relevant literature and design of the curriculum, and piloting of the methodology. Students' perspectives were engaged throughout the development process to ensure the curriculum was relevant to the lives of youth living in violent communities. The curriculum is the first to be built on the Virtues in Action framework in NTCA countries. Lessons learned are shared for CSD program design and implementation in other contexts with high levels of violence.
\end{abstract}

Key words: positive youth development, character strengths, curriculum development, Values in Action (VIA), Central America, Glasswing International

\section{Introduction}

All too many young people around the world grow up in violent contexts with few resources for promoting their positive development. Despite declining homicide rates over the past decade, the current levels of violence in El Salvador, Honduras, and Guatemala-three countries that make up the Northern Triangle of Central America (NTCA)-are some of the highest in the world. In fact, the NTCA is one of the deadliest places for young boys aged 10 to 19 (UNICEF,

(cc) EY New articles in this journal are licensed under a Creative Commons Attribution 4.0 License. This journal is published by the University Library System, University of Pittsburgh and is cosponsored by the University of Pittsburgh Press. The Journal of Youth Development is the official peer-reviewed publication of the National Association of Extension 4-H Youth Development Professionals and the National AfterSchool Association. 


\section{Designing a Character Strengths Development Program}

2017). Additionally, during the last decade, these countries experienced an average $13 \%$ reduction in the educational enrollment rate (The World Bank, 2020), with over $18 \%$ of students in El Salvador reporting they dropped out of school due to delinquency (Ministerio de Educación, Ciencia y Tecnología, 2019). There is an urgent need to reduce the vulnerability of youth living in these contexts to involvement in violence, to prevent them from suffering the devastating effects of violence in their communities, and to promote their positive development. Providing youth with tools to help promote the character strengths of youth living in violent contexts is critical.

Glasswing International was founded in 2007 in San Salvador, El Salvador to address the root causes and consequences of violence and poverty in Central America through education and health programs that empower youth and the communities they live in. Glasswing has permanent programming in 120 public schools. To date, the organization also has provided training and support in over 1,900 after-school extracurricular clubs, serving more than 52,000 young people, in nine different countries. Glasswing designed a curriculum called the Character Strengths Development (CSD) or Programa de Bienestar, Construcción de Fortalezas de Carácter to promote the character strengths of youth in their programs and to increase their positive development and psychological well-being. Glasswing's curriculum has been framed on the Virtues in Action (Peterson and Seligman, 2004) framework, the first such curriculum to exist in NTCA countries. The character strengths curriculum serves as a complement to Glasswing's after-school activities. This paper describes the design process and piloting of the curriculum and provides lessons learned for other organizations looking to promote character strengths of youth living in violent contexts and thereby promote their positive development.

\section{Background}

\section{The Northern Triangle of Central America}

El Salvador, Guatemala, and Honduras constitute what is known as the NTCA. These countries face similar challenges related to the positive development of youth and have gained worldwide attention because of gang-related violence that has produced large-scale internal displacement and migration flows northward (Médecins Sans Frontières, 2018). Central America is one of the sub-regions with the highest global homicide rates on record and the northern triangle countries are the most violent countries within this region (Geneva Declaration Secretariat, 2015). Homicide rates have surpassed epidemic levels in the last decade and, despite the sustained downward trend in recent years, there were 43.6 violent deaths per 100,000 inhabitants in Honduras in 2019 (Infosegura, 2020c), 21.5 in Guatemala (Infosegura, 2020b), and 35.8 in El 


\section{Designing a Character Strengths Development Program}

Salvador (Infosegura, 2020a). The homicide rates are higher in areas of more than 50,000 inhabitants, revealing the urban nature of violence and crime in the sub-region (United Nations Office on Drugs and Crime [UNODC], 2013). Homicide rates in the most populated cities are higher than the national average, yet violent hotspots prevail in both rural and urban areas.

In the Americas, youth aged 15 to 29 years constitute the largest group of victims from homicides (UNODC, 2013). In the NTCA countries, 60 percent of victims are young men between ages 15 and 34. Young men are also the main perpetrators of violence, and they comprise the majority of gang membership (The World Bank, 2011). However, victims of violence are not just men, as is evident from indicators on violence against women in the subregion, with especially high femicide rates in Honduras and El Salvador (Government of El Salvador, 2019; Luciano et al., 2019; Ramos, 2011).

Gangs are perceived as the main driver of violence in the NTCA countries. These groups control neighborhoods or territories and constitute a sub-culture that makes crime a way of life (Sida, 2008). Gang membership is linked with epidemic levels of violent crime and drug trafficking and consumption. Studies identifying the risk factors for young people to become either perpetrators or victims of violence reveal a multitude of factors including societal, such as unemployment, inactivity, migration, and poverty conditions; community factors, such as low educational attainment, school violence, and availability of firearms; interpersonal factors, such as dysfunctional families and peers who are gang members; and individual factors, such as alcohol abuse and lack of positive identity (The World Bank, 2011). While there are many programs in the NTCA countries focused on preventing negative behaviors and protecting young people from violence, there are fewer programs, and even fewer curricula, focused on promoting character strengths of youth to promote their positive development.

\section{Character Strengths and Youth Development in Violent Contexts}

Exposure to violence and life-threatening experiences not only threaten the physical health of young people but also challenge their healthy social-emotional development. Some studies have found direct relation between exposure to negative events, such as political violence, wars, or terrorist attacks and adverse consequences in children, from distress to acute trauma (Garbarino \& Kostelny, 1996; Lavi \& Slone, 2011). Likewise, studies suggest that there are mediating variables in this relation, making a child or young person more prone or less prone to presenting symptoms of distress or trauma after experiencing violent situations. 


\section{Designing a Character Strengths Development Program}

Existing literature has pointed out the important role of character strengths when dealing with traumatic situations. For example, Tedeschi and Calhoun (1995) suggest that there is a positive association between character strengths and post-traumatic growth, defined as the positive psychological effect following a potentially traumatic event. In this sense, the individual's level of functioning after the traumatic experience exceeds the pre-trauma state (Hall et al., 2008). According to Bonanno (2004), character strengths also play a role in building resilience, a theory underscored by Shoshani and Slone's (2016) study on the role of resilience among youth living in war contexts, as well as other authors that suggest a moderation effect of self-control (Lavi \& Slone, 2011) and of hope and spiritual meaning (Ai et al., 2005). Studies also show that character strengths help individuals manage problems more effectively, as positive character strengths are linked to decreased levels of stress, improved coping in the workplace, less friction in classrooms, and less depression, among others (Niemiec \& McGrath, 2019). Besides, other studies indicate that external factors also mediate in this relation, for instance, gender or demographic characteristics (Hall et al., 2008), and family variables, such as harsh parenting or parenting distress (Miller \& Jordans, 2016).

Despite existing research regarding the role of character strengths for individuals in war-torn settings or after a terrorist attack, evidence of effective character strength development programing designed for youth from countries with high levels of non-war-related violence, such as the NTCA countries, remains scarce. Yet, according to Shoshani and Slone's (2016) classification of violent events, youth living in Central America are exposed to moderate to severe levels of violence. For example, Portillo (2013) presents data from a youth program in San Salvador, El Salvador showing that $51 \%$ of participants reported being direct victims of violence within their communities during the previous year, $20 \%$ reported suffering beatings, $15 \%$ had been attacked with a weapon, and $19 \%$ had been robbed. In addition, $98 \%$ of the participants reported being exposed to violence during the previous year, with $79 \%$ having witnessed someone being beaten, $33 \%$ saw someone being wounded, and $51 \%$ witnessed someone being shot.

Based on existing positive youth development (PYD) research in which character strengths are considered to be related to PYD, well-being and life satisfaction, as they are related to happiness (Park et al., 2009), coping mechanisms (Harzer \& Ruch, 2015), and decision making (Jordan \& Rand, 2018)), and Glasswing's own research and investment in promoting the character strengths of the young people they serve, the organization decided to design a curriculum aimed at promoting character strengths of youth living in NTCA countries. There was no existing CSD curriculum Glasswing could find to build on that had been used with youth in 


\section{Designing a Character Strengths Development Program}

NTCA countries. For this reason, Glasswing sought to establish one on its own and after an extensive review of the CS literature, Glasswing decided to build its curriculum around the Values in Action (VIA) Classification of Character Strengths framework (Peterson \& Seligman, 2004).

\section{The Values in Action Classification of Character Strengths}

The VIA (Peterson \& Seligman, 2004) theoretical model considers 24 character strengths that are reflective of the following six virtues: wisdom, courage, humanity, justice, temperance, and transcendence. According to Peterson and Seligman, the virtues selected in the framework are the six core moral virtues that are valued across different cultures and over time, while character strengths are personality traits that comprise good character, are positively valued, and help individuals to produce desirable outcomes. Character strengths are revealed in one's behavior, thoughts, and feelings. The VIA has been implemented and tested in many countries (McGrath, 2014; McGrath et al., 2017) but it has not yet been used in PYD research or programming with the NTCA countries.

In this paper, the authors present the methodology used by Glasswing for the design and implementation of the VIA-based CDS curriculum and lessons learned in the hopes of providing guidance to other organizations interested in implementing CDS interventions in similar contexts.

\section{Methods}

In this section, the authors describe the three-stage process that was used to design and pilot the CSD curriculum. In Stage 1, the team recruited youth to participate in the study and developed a consultative process in which youth identified the key VIA character strengths that assist them in coping with the violence in their communities in the short-term and thrive in life in the mid- and long-term. In the second stage, the team designed a context and ageappropriate character strengths curriculum for youth attending public schools in these countries through a collaborative process and literature review. Finally, in the third stage, the team piloted the methodology with students and instructors from El Salvador and reviewed key learning so as to make any necessarily adjustments to the curriculum before implementation of the curriculum in seven additional public schools in Honduras, Guatemala, and El Salvador. 


\section{Designing a Character Strengths Development Program}

\section{Stage 1: Recruitment of Participants and Consultative Process}

Glasswing International was very intentional in its goals to engage young people in the design process of the curriculum. Given the VIA had not been used in NTCA countries before to promote the character strengths and positive development of youth, it was critical to engage the voices of youth so that they could create a VIA-based curriculum relevant to these specific youth living in these specific countries. As such, after recruiting youth to participate in the curriculum development, in each country, the team implemented a consultative process to identify the character strengths from the VIA that were most relevant to their lives and their ability to face the challenges of living in highly violent contexts.

\section{Recruitment of Participants to Assist in Design of Curriculum:}

In order to design the CSD curriculum through a consultative process, Glasswing visited schools in El Salvador, Honduras, and Guatemala during early January 2019. The objective was to enroll selected students from schools in the Northern Triangle located in poor urban communities characterized by violence and large migration flows, such as the program's target population. In these visits, students received parental authorization forms and were asked to return them signed by a parent or caregiver. The team returned to schools to check parent authorizations and enroll students. The only criteria for participation were (a) the ability to attend the singlesession consultative process that took place on a specific date per country and (b) having signed authorization from their parents.

A total of 64 students from these schools were chosen. The participants included 21 youth from San Salvador (El Salvador); 24 from Guatemala City, Mixco, and Villa Nueva (Guatemala); and 19 from San Pedro Sula, Choloma, and Villanueva (Honduras). Students ranged in age from 13 to 17 .

\section{Consultative Process}

- The consultative session with the youth took place in mid-January 2019 and involved three stages: (a) creating a safe space for youth to discuss topics related to their lives and character strengths, (b) describing each of the character strengths in the VIA to youth and collecting youth perceptions of each of the strengths, and (c) group and individual reflection on character strengths that are most relevant to their lives. The same procedure was implemented in each country and took about 5 hours to complete (including short breaks).

- Creating a safe space: To promote confidence and create a safe and comfortable space, the first stage began with an ice-breaker activity called "The Vase," which is based on a 


\section{Designing a Character Strengths Development Program}

restorative practice of Costello et al. (2013). The objective of this activity was to foster an atmosphere of openness and reflection. Participants were divided into groups by school and were asked to mention positive characteristics of their classmates. Then each participant drew a vase with flowers, in which each flower represented a positive characteristic that classmates had assigned them. Students shared the results of this activity with the group.

- Describing the VIA to the participants and collecting their perceptions. In the second stage, students participated in a "rally through the virtue stations." It consisted in students walking through a circuit of six stations, one for every virtue from the VIA framework. As participants went through each station, a mentor supported them in understanding and discussing the meaning of each virtue and the character strengths associated with each virtue.

- Reflection: In Stage 3, the aim was to help participants to identify the character strengths from the VIA framework that were the most relevant in helping them face the challenges of their violent contexts and to thrive in life. To accomplish this, students were separated into smaller groups, and used a circle format called "the fishbowl" to decide which character strengths were relevant in their context (Costello et al., 2011). Drawing on a tool from the "I am READY" curriculum of Catholic Relief Services, in which the NGO staff has received training, Glasswing created a context- and ageappropriate story called "Historia de Lily y Dan." First, participants were asked to read about this fictional character who had faced her own difficult situation, similar to that of many children from the region: living with a single mother in a risky environment, and spending afternoons or even nights alone or unattended. The whole story has 13 chapters, which were separated into two chapters per fishbowl, for a total of 6 groups, and a final chapter that all groups had to read. Participants were then asked to identify which character strengths could help the protagonist from the fictional story overcome the obstacles presented in the story. In this way, participants did not have to share about their own lives or situations and could express their opinions freely. The Glasswing team captured this information. To systematize the information, staff counted the frequency with which each strength was selected.

Then, participants were asked to identify strengths that may be useful in their own lives, writing them on a sheet of paper that they put into a box anonymously. The goal of having students anonymously write down the most important character strengths needed to manage their own personal situations in the violent contexts they live in and to thrive in their lives was that they could be open and honest and not be swayed by their peers. 
The virtues, as defined in the VIA framework, selected with highest frequency for both the fictional character and personal experience were courage, temperance, and transcendence. The strengths with the highest selection rate for the virtue of courage were bravery and perseverance; for temperance, self-regulation and prudence; and for transcendence, gratitude and appreciation of beauty and excellence. Another character strength with high frequency was social intelligence which is associated with the humanity virtue. The top 10 strengths selected, by country, are presented in Table 1 , and the character strengths identified in the consultative process are presented in Figure 2.

Table 1. Distribution of the Top 10 Character Strengths Prioritized by Participants in Consultation Process by Country

\begin{tabular}{|l|l|l|l|l|l|}
\hline \multicolumn{2}{|c|}{ El Salvador } & \multicolumn{2}{c|}{ Guatemala } & \multicolumn{2}{c|}{ Honduras $^{\mathrm{a}}$} \\
\hline Strength & $\%$ & \multicolumn{1}{c|}{ Strength } & $\%$ & \multicolumn{1}{c|}{ Strength } & $\%$ \\
\hline Bravery & $86 \%$ & $\begin{array}{l}\text { Appreciation of beauty } \\
\text { and excellence }\end{array}$ & $94 \%$ & Bravery & $61 \%$ \\
\hline Social intelligence & $83 \%$ & Perseverance & $79 \%$ & Perseverance & $26 \%$ \\
\hline Self-regulation & $81 \%$ & Gratitude & $73 \%$ & Self-regulation & $26 \%$ \\
\hline Prudence & $76 \%$ & Courage & $24 \%$ \\
\hline Hope & $69 \%$ & Humanity & $71 \%$ & Integrity & $21 \%$ \\
\hline Fairness & $67 \%$ & Social intelligence & $65 \%$ & Fairness & $18 \%$ \\
\hline Perseverance & $64 \%$ & Curiosity & $63 \%$ & Forgiveness & $18 \%$ \\
\hline Judgement & $60 \%$ & Humor & $60 \%$ & Prudence & $18 \%$ \\
\hline Leadership & $57 \%$ & Creativity & $58 \%$ & Love & $18 \%$ \\
\hline Love & $55 \%$ & Love of learning & $54 \%$ & Judgement & $16 \%$ \\
\hline
\end{tabular}

Note. This table shows the percentage of participants that reported the strength was highly important to them.

a Nothing different was done methodologically in Honduras compared to Guatemala and El Salvador, yet there is a marked difference in the percentages for Honduras compared to the other two countries. We believe that there was a different understanding of the rules in this group, which led each participant to choose fewer virtues in each vote. Despite that, one can see that the highest strengths in the ranking are similar in Honduras.

${ }^{b}$ Value treated as a character strength for this stage of the consultation in Guatemala. At the time of the consultation, two virtues-courage and humanity-were used as strengths in Guatemala. Since the rest of strengths included in these two virtues were not included separately in the consultation, we are confident that this change in the methodology in one country has not affected the overall analysis and results. 


\section{Figure 2. Top 10 Character Strengths Prioritized by NTCA Youth in Consultation}

\section{Process}

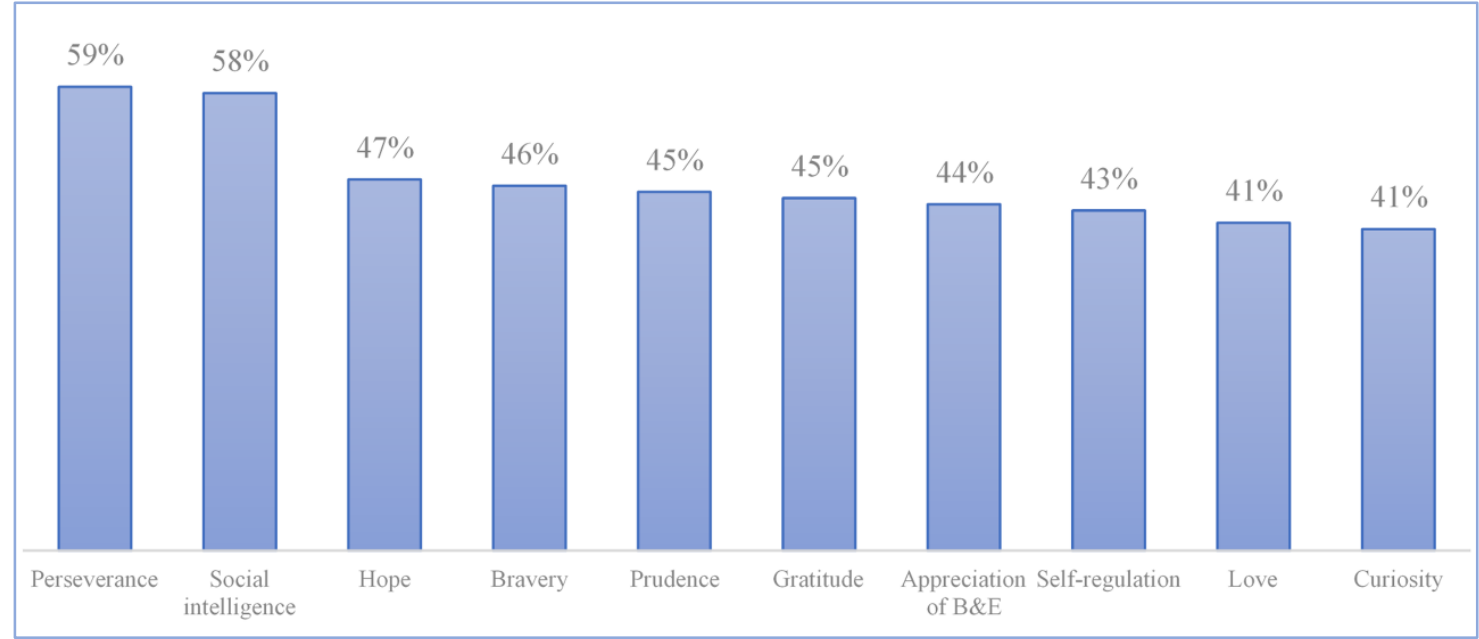

Note. This figure shows the average percentage of participants who reported a character strength was "highly important" in all three NTCA countries.

Overall, the students demonstrated high levels of participation in the consultative process with robust group discussions and insightful questions and comments.

\section{Stage 2: Method for CSD Curriculum Design and Final Design for Pilot Testing}

To perform this task, Glasswing partnered with a team of experts in education from the Leadership and Development Center (LDC). ${ }^{1}$ This stage included two activities: (a) review of the existing literature on interventions oriented to promote PYD and (b) design of the CSD curriculum.

\section{Literature Review}

In addition to the consultative process with youth, Glasswing conducted a literature review to identify character strengths that show evidence of promoting PYD and to triangulate the results of the literature review with the results of the consultation. The literature review focused on character strength needs in youth in contexts of social and economic vulnerability (e.g., Cunningham et al., 2008; Morales, 2010; Noell, 1998; Sánchez-Elvira, 2004; Tough, 2016). Special attention was paid to research that places children and youth as the center of the

\footnotetext{
${ }^{1}$ The LDC specializes in the design of leadership and teamwork programs to institutions and firms, adapted to their needs. It uses an active learning methodology that combines theory and applied activities. More information is available at http://liderazgo.esen.edu.sv/
} 


\section{Designing a Character Strengths Development Program}

research process and as an important source of information. The character strengths that converged in the triangulation process included perseverance, social intelligence, selfregulation, hope, creativity, and perspective. Since bravery was one of most frequently selected strengths among students, Glasswing decided to include it in the curriculum, even though it was not identified in the literature review. Glasswing gave more weight to the opinion of the young people at this point, considering that listening to the youth is relevant to the design of a curriculum for their well-being. These seven character strengths then constituted the core of the CSD curriculum that was developed.

\section{Final Design of the CSD curriculum for Piloting}

Considering the literature review implemented by Glasswing International and the results from the consultation process from Stage 1, the LDC team supported Glasswing in the development of the training program hand-in-hand with Glasswing. The process intended to design a curriculum that responds accurately to the needs and areas that are useful for young people from the NTCA countries, using the core character strengths selected from the triangulation described previously.

The main objective of this stage was creating a curriculum that taught Glasswing clubs' participants character strengths, so they could increase their well-being and thrive in their lives. The specific objectives of this activity stage were (a) developing positive psychological resources that might motivate beneficial behaviors and (b) developing psychological resources that could prevent or reduce harmful behaviors.

This activity was implemented right after Glasswing ended the consultation process, by midFebruary 2019, in coordination with the LDC. This partnership with the LDC aimed to combine Glasswing expertise in the context and their learning of youths' needs in terms of character strengths from the first stage and LDC's experience in the development of educational materials for youth. Glasswing's team constituted experts in positive psychology and education; on the LDC side, the team included experts in educational curriculum and leadership.

The final design includes activities oriented to teach the seven character strengths in 32 sessions. Each of these sessions are planned to last between 20 and 60 minutes each. The CSD curriculum structure includes two types of sessions: learning and reflection. Learning sessions last 1 hour, and reflection sessions are shorter, between 20 and 30 minutes. After these CS sessions, participants engage in extracurricular activities, such as football, art, robotics, and dance. 


\section{Designing a Character Strengths Development Program}

The learning sessions are aimed at providing students with a clear understanding of each of the seven character strengths by explaining the theory behind the framework. Each learning session is followed by three or four reflection sessions. In the reflection sessions, an active learning methodology is implemented, which places the student at the center of the learning experience and motivates participation through individual guided activities. The guide contains short exercises through which the participant can analyze her context and behaviors and propose solutions for her problems or set goals for the future. Then, the curriculum is reinforced through group activities that are performed in the rest of the session, while extracurricular activities are carried out. ${ }^{2}$

In addition to the design of the structure of these sessions and methodology, Glasswing and the LDC created a guide of activities to be developed on each reflection session and made a methodological transmission to a group of volunteer leaders who were in charge of training the whole volunteer team in the three countries. In each reflection session, participants practice one of the strengths, until they complete the whole program for the seven character strengths included in the curriculum. In each session, they are asked to reflect on situations of their daily life, guided by a volunteer educator previously trained in the CSD curriculum and guide of activities.

The guide contains context- and age-appropriate graphic material and exercises for reflection. For example, the activities to practice and develop perseverance invite the participants to set a midterm goal and create a map identifying the possible obstacles they will need to overcome in order to reach this goal. For 4 weeks, with the support of their volunteer educators, they monitor if they are on the right track to achieve their goal. Likewise, they work on their life objectives (long-term goals and aspirations), setting midterm goals, and recognizing the actions to achieve these objectives. They are also invited to think about the guiding values they wanted to choose for their life. The examples used are always focused on the age and condition of the participants. All these activities were developed in physical worksheets and saved by the participants.

\footnotetext{
${ }^{2}$ For more details about the structure of the curriculum sessions, please contact Glasswing International staff at https://glasswing.org/contact/
} 


\section{Designing a Character Strengths Development Program}

\section{Stage 3: Feedback Sessions and Key Learning From the Design of CSD Curriculum}

Glasswing and the LCD team had a test session of dynamics and activities with young participants of Glasswing's regular after-school program. After performing a reflection and hands-on activities, they reported that the intervention was interesting and that they would be willing to attend a program that includes these types of activities as part of their curriculum. In addition, they provided feedback on the examples and cases used in the reflection activities, suggesting they should be more appropriate and contextualized for middle school students. These suggestions were considered for the final curriculum structure and implementing guide for tutors.

The team also had feedback sessions with a group of volunteers who usually teach in Glasswing's regular after-school program. In this session, the team explained and described the curriculum and the implementing guide in order to receive feedback and recommendations on how to adjust the materials to the needs and contexts where they implement these programs. The volunteers recommended defining learning objectives that are clearer and separated from the practical objectives. In addition, considering this feedback session and with the support of volunteers, the team made the decision to rearrange the total time per session; we reduced the time dedicated to extracurricular activities to invest more time to the implementation of the CSD curriculum.

\section{Next Steps}

Glasswing has thus far implemented the CSD curriculum in seven public schools through its after-school programs in Guatemala, Honduras, and El Salvador. In total, 426 students voluntarily enrolled in sessions as a complement to Glasswing's after-school club program that includes sports, art, and dance activities. Students attended the character development sessions once a week for 7 to 8 months of the 2019 academic year. This intervention was part of an impact evaluation that studies the effect of a positive development curriculum in youth development and well-being. The team has collected baseline and mid-term follow-up data, but due to public health and social measures in the context of COVID-19, we were not able to collect long-term follow-up data. During 2021, the team will collect qualitative data through focus groups with teachers, parents and caregivers of participants to understand the short-term effects and to qualitatively assess long-term effects of the intervention. The results of the evaluation will be published separately. 


\section{Author Note}

This project was made possible through the support of a grant from Templeton World Charity Foundation, Inc. The opinions expressed in this publication are those of the authors and do not necessarily reflect the views of Templeton World Charity Foundation, Inc., their employers, or governments.

Correspondence concerning this article should be directed to Betsabé Vásquez, bvasquez@glasswing.org.

\section{References}

Ai, A., Cascio, T., Santangelo, L., \& Evans-Campbell, T. (2005). Hope, meaning, and growth following the September 11, 2001, terrorist attacks. Journal of Interpersonal Violence, 20(5), 523-548. https://doi.org/10.1177/0886260504272896

Bonanno, G. (2004). Loss, trauma, and human resilience: Have we underestimated the human capacity to thrive after extremely aversive events? The American Psychologist, 59(1), 20-28. https://doi.org/10.1037/0003-066X.59.1.20

Costello, B., Wachtel, J., \& Wachtel, T. (2013). Círculos restaurativos en los centro escolares: Fortaleciendo la comunidad y mejorando el aprendizaje. International Institute for Restorative Practices.

Cunningham, W., McGinnis, L., Verdú, R. G., Tesliuc, C. M., \& Verner, D. (2008). Youth at risk in Latin America and the Caribbean: Understanding the causes, realizing the potential. https://doi.org/10.1596/978-0-8213-7520-4

Garbarino, J., \& Kostelny, K. (1996). The effects of political violence on Palestinian children's behavior problems: A risk accumulation model. Child Development, 671), 33-45. https://doi.org/10.2307/1131684

Geneva Declaration Secretariat. 2015. Global burden of armed violence 2015: Every body counts. Cambridge University Press. https://doi.org/10.1017/CBO9781107707108

Government of El Salvador. (2019). Informe sobre los feminicidios o los asesinatos de mujeres por razón de género. Retrieved January 30, 2021, from https://www.ohchr.org/Documents/Issues/Women/SR/Call/El\%20Salvador.pdf

Hall, B., Canetti, D., \& Hobfoll, S. (2008). Posttraumatic growth following terrorism: A review of several studies in Israel. In P. Buchwald, T. Ringeisen, \& M. Eysenck (Eds.), Stress and anxietyApplication to life span development and health promotion (pp. 111-120). Logos Verlog. 
Journal of Youth Development | http://jyd.pitt.edu/ | Vol. 16 Issue 2-3 DOI 10.5195/jyd.2021.1032

Designing a Character Strengths Development Program

Harzer, C., \& Ruch, W. 2015. The relationships of character strengths with coping, work-related stress, and job satisfaction. Frontiers in Psychology, 6. https://doi.org/10.3389/fpsyg.2015.00165

Infosegura. (2020a). El Salvador archivos. Author. Retrieved January 30, 2021, from https://www.infosegura.org/seccion/el-salvador/

Infosegura. (2020b). Guatemala archivos. Author. Retrieved January 30, 2021, from https://www.infosegura.org/seccion/guatemala/

Infosegura. (2020c). Honduras archivos. Author. Retrieved January 30, 2021, from https://www.infosegura.org/seccion/honduras/

Jordan, M., \& Rand, D. 2018. The role of character strengths in economic decision-making. SSRN Electronic Journal, 13(4), 382-392. https://doi.org/10.2139/ssrn.3171194

Lavi, I., \& Slone, M. (2011). Resilience and political violence: A cross-cultural study of moderating effects among Jewish- and Arab-Israeli youth. Youth \& Society, 43(3), 845-872. https://doi.org/10.1177/0044118X09353437

Luciano, D., Hidalgo, N., Acuña, N., \& Urban, A.-M. (2019). Femicidio en Honduras. Inter-American Development Bank. https://doi.org/10.18235/0001584

McGrath, B. (2014). Character strengths in 75 nations: An update. The Journal of Positive Psychology, 10(1), 41-52. https://doi.org/10.1080/17439760.2014.888580

McGrath, B., Greenberg, M., \& Hall-Simmonds, A. (2017). Scarecrow, Tin Woodsman, and Cowardly Lion: The three-factor model of virtue. The Journal of Positive Psychology, 13(4), 373-392. https://doi.org/10.1080/17439760.2017.1326518

Médecins Sans Frontières. (2018). Forced to flee Central America's northern triangle: A neglected humanitarian crisis. Author. https://www.msf.org/sites/msf.org/files/msf forced-to-flee-centralamericas-northern-triangle e.pdf

Miller, K., \& Jordans, M. (2016). Determinants of children's mental health in war-torn settings: Translating research into action. Current Psychiatry Reports, 18(58). https://doi.org/10.1007/s11920-016-0692-3

Ministerio de Educación, Ciencia y Tecnología. (2019). Educational Census. Retrieved July 1, 2020, from https://www.mined.gob.sv/estadisticas-educativas/item/6116-bases-de-centros.html

Morales, E. (2010). Linking strengths: Identifying and exploring protective factor clusters in academically resilient low-socioeconomic urban students of color. Roeper Review, 32(3), 164-175. https://doi.org/10.1080/02783193.2010.485302

Niemiec, R., \& McGrath, R. (2019). The power of character strengths: Appreciate and ignite your positive personality. VIA Institute on Character.

Noell, J. F. (1998). La búsqueda de factores protectores del fracaso escolar en niños en situación de riesgo mediante un estudio de casos. Revista de Investigación Educativa, 16(1), 47170. 
Journal of Youth Development | http://jyd.pitt.edu/ | Vol. 16 Issue 2-3 DOI 10.5195/jyd.2021.1032

Designing a Character Strengths Development Program

Park, N., Peterson, C., \& Ruch, W. 2009. Orientations to happiness and life satisfaction in twenty-seven nations. The Journal of Positive Psychology, 4(4), 273-279.

https://doi.org/10.1080/17439760902933690

Peterson, C., \& Seligman, M. 2004. Character strengths and virtues: $A$ handbook and classification. American Psychological Association, Oxford University Press.

Portillo, N. 2013. Evaluación de la estrategia de desarrollo juvenil para la prevención de la violencia social en San Salvador.

Ramos, E. (2011). Explosión del femicidio en El Salvador. http://www.redicces.org.sv:80/jspui/handle/10972/297

Sánchez-Elvira, Á. (2004). Los pilares y recursos de la psicología positiva en el crecimiento personal. In M. Rodríguez Zafra (Ed.), Crecimiento personal: Aportaciones de oriente y occidente (pp. 45-80). Desclée de Brower.

Shoshani, A., \& Slone, M. 2016. The resilience function of character strengths in the face of war and protracted conflict. Frontiers in Psychology, 6. https://doi.org/10.3389/fpsyg.2015.02006

Sida. 2008. Maras and youth gangs, community and police in Central America [Summary of a regional and multidisciplinary study]. https://www.sida.se/contentassets/df3445cd986943068782e217e605406e/maras-and-youthgangs-community-and-police-in-central-america 1175.pdf

Tedeschi, R. G., \& Calhoun, L. G. 1995. Trauma and transformation. SAGE.

Tough, P. (2016). Helping children succeed: What works and why. Houghton Mifflin Harcourt.

UNICEF. (2017). Violent deaths. UNICEF DATA. https://data.unicef.org/topic/childprotection/violence/violent-deaths/

United Nations High Commissioner for Refugees. (2016). Call to action: Protection needs in the northern triangle of Central America. UNHCR Discussion paper. A proposal for a strategic regional response. https://www.refworld.org/docid/57a8a8844.html

United Nations Office on Drugs and Crime. 2013. Global study on homicide. https://www.unodc.org/documents/data-andanalysis/statistics/GSH2013/2014 GLOBAL HOMICIDE BOOK web.pdf

The World Bank. 2011. Crime and violence in Central America: A development challenge.

The World Bank. 2020. The World Bank data. Retrieved February 4, 2021, from https://data. worldbank.org/indicator/SE.SEC.ENRR?locations=SV-HN-GT 